\title{
NOVOS LETRAMENTOS E DOCÊNCIA NA EDUCAÇÃO A DISTÂNCIA'
}

\author{
NEW LITERACIES AND TEACHING IN DISTANCE EDUCATION
}

NUEVOS LETRAMIENTOS Y LA ENSEÑANZA EN EDUCACIÓN A DISTANCIA

\section{Marta Fernandes Garcia ${ }^{1}$ \\ Marcelo El Khouri Buzato ${ }^{2}$ \\ Cássio Ricardo Fares Riedo ${ }^{3}$ \\ Dirceu da Silva ${ }^{4}$}

\begin{abstract}
RESUMO
O presente texto problematiza os diferentes modelos de letramento vigentes nos estudos da linguagem para se pensar as práticas sociais na educação superior a distância no Brasil. O estudo aponta o modelo teórico dos transletramentos como uma referência útil à reflexão sobre e ação de apropriação tecnológica crítica do aparato tecnológico da EAD online, por estar tal modelo inserido em um novo paradigma sociocultural e contribuir para a superação de práticas e concepções com viés instrumentalista, determinista e utilitarista na educação a distância. Ao qualificar as práticas e modos de produção de sentido como atravessamentos de papéis, mídias e linguagens por sujeitos que buscam superar a dimensão meramente funcional dos letramentos contemporâneos, o modelo dos transletramentos favorece o desenvolvimento dos atores educacionais envolvidos na docência em EaD em uma outra lógica, mais progressista e crítica, voltada para qualificar o processo formativo a distância e romper com programas de formação com viés puramente mercadológico.
\end{abstract}

PALAVRAS-CHAVE: Novos Letramentos. Apropriação Tecnológica. Formação de Professores. Educação a Distância.

ABSTRACT: This paper discusses the different models of literacy in language studies to consider social practices in higher distance education in Brazil. The study notes that the transliteracies theoretical model provides a useful reference for reflection and action upon critical appropriation of the technological apparatus of online distance education, as such a model contributes to overcoming practices and concepts typical of the instrumentalist, deterministic and utilitarian bias in distance education. By qualifying meaning making

\footnotetext{
${ }^{1}$ Doutoranda em Educação pela Universidade Estadual de Campinas (UNICAMP) - Brasil. Professora no Instituto Federal de São Paulo (IFSP), Cubatão, SP - Brasil. Email: marta fgarcia@yahoo.com.br

2 Doutor em Linguística Aplicada pela Universidade Estadual de Campinas (UNICAMP) - Brasil. Professor Doutor do Departamento de Linguística Aplicada da Universidade Estadual de Campinas (UNICAMP), Campinas, SP Brasil. Email: marcelo.buzato@gmail.com

${ }^{3}$ Doutorando em Educação pela Universidade Estadual de Campinas (UNICAMP), Campinas, SP - Brasil.. E-mail: cfriedo@yahoo.com

${ }^{4}$ Doutor em Educação pela Universidade de São Paulo, SP (USP) - Brasil. Professor Doutor do Departamento de Educação e Práticas Culturais da Universidade Estadual de Campinas (UNICAMP), Campinas, SP - Brasil. E-mail: dirceu@unicamp.br
}

Submetido em: 10/12/2015 - Aprovado para publicação em: 17/05/2016
(C) ETD- Educação Temática Digital
Campinas, SP
v.19 n.1
p. 211-233 jan./mar. 2017 
practices and modes as traversals of roles, media and languages by literate subjects that attempt to overcome a merely functional dimension of contemporary literacies, the transliteracies model supports educational actors involved in teaching in distance education in a more progressive and critical fashion, with the aim of breaking with training programs that have a purely marketing bias.

KEYWORDS: New Literacies. Technological Appropriation. Teacher Training. Distance Education.

RESUMEN: El artículo analiza los diferentes modelos de letramiento en vigor en estudios de lenguaje para pensar acerca de las prácticas sociales en educación superior a distancia en Brasil. El estudio señala el modelo teórico de los transletramientos como una referencia útil para la reflexión y la acción de apropiación tecnológica crítica de los aparatos tecnológicos de la educación a distancia, por ser un modelo insertado en un nuevo paradigma y por contribuir para superar las prácticas y conceptos con sesgo instrumentista, determinista y utilitarista en la educación a distancia. A calificar las prácticas y los modos de producción de sentido como cruces de funciones, medios y lenguajes para las personas que buscan superar la dimensión puramente funcional de letramientos contemporáneos, el modelo de transletramentos favorece la participación de los actores educativos implicados en la enseñanza en la educación a distancia en una lógica diferente, más progresista y crítica, dirigida a calificar el proceso de formación a distancia y romper con los programas de formación que tiene sesgo puramente mercadológico.

PALABRAS CLAVE: Nuevos Letramientos. Apropiación Tecnológica. Formación del Profesorado. Educación a Distancia.

\section{INTRODUÇÃO}

Presenciamos no campo da educação superior um crescimento vertiginoso da modalidade a distância no Brasil desde 2001 e, sobretudo, na área das licenciaturas. Isso se dá, em boa parte, por conta da ampliação do acesso à internet e pela adoção da Educação a Distância (EaD) em políticas públicas para atingir metas de formação inicial e continuada de professores, desejo expresso na LDB no 9394/96: “Art. 80․ O Poder Público incentivará o desenvolvimento e a veiculação de programas de ensino a distância, em todos os níveis e modalidades de ensino, e de educação continuada" (BRASIL, 1996). Inclusive, o Plano Nacional de Educação - PNE 2014 - 2024 (BRASIL, 2014) também se manifesta favorável ao uso das Tecnologias de Informação e Comunicação (TIC) na educação para alcançar suas metas de ampliação da oferta de vagas no ensino superior e em cursos de pós-graduação stricto sensu, especialmente por meio da Universidade Aberta do Brasil.

A questão do acesso é, sem dúvida, importante e necessária, porém é preciso avançar e buscar a concretização de elementos que garantam a permanência e a qualidade do processo formativo a distância. Neste sentido, os Referenciais de Qualidade para a Educação Superior a Distância (BRASIL, 2007) evidenciam aspectos que favorecem a qualidade, dentre eles: (1) integração e interação entre professores, tutores e estudantes; (2) formação, supervisão e avaliação dos tutores e outros profissionais que atuam nos pólos e (3) integração das diferentes mídias, explorando a convergência e integração entre

(C) ETD-Educação Temática Digital Campinas, SP v.19 $\quad$ n.1 $\quad$ p. 211-233 jan./mar. 2017 
materiais impressos, radiofônicos, televisivos, de informática, de videoconferências e teleconferências, dentre outros, na perspectiva da construção do conhecimento e favorecendo a interação entre os múltiplos atores. Estes itens dos referenciais demonstram uma preocupação com a prática de professores tutores ${ }^{5}$ e professores conteudistas e com o uso das tecnologias e diferentes mídias e sua integração no processo formativo, apontando para a necessidade de formação de um novo tipo de sujeito letrado. É nesta direção, que a preocupação central deste trabalho é pensar a contribuição das teorias sobre os novos letramentos para a formação do professor na sociedade contemporânea. Mais especificamente, a formação do formador de futuros professores, que exerce sua prática em ambientes virtuais de aprendizagem, local, por vezes, subutilizado.

Os diferentes ambientes virtuais trazem consigo diferentes modelos de pensar e organizar a comunicação e a interação entre os sujeitos envolvidos no processo de ensinoaprendizagem. Somado a isso, profissionais com diferentes concepções sobre Educação a Distância (EaD) e formação de professores habitam este espaço, conduzindo o processo formativo por caminhos, muitas vezes, mais instrumentais, mercadológicos e reducionistas do que condizentes com os ideias de cidadania, democracia e desenvolvimento humano e social.

Posto isto, a reflexão sobre a prática e apropriação tecnológica de professores da educação a distância se torna ainda mais necessária quando constatamos a polidocência (MILL, 2010) existente nos ambientes virtuais e o despreparo de muitos profissionais para atuar nesta modalidade, que apresenta especificidades e desafios para além do ensino tradicional (COSTA; HARRIS, 2005; SANTOS; TRACTENBERG; PEREIRA, 2005; OLIVEIRA; HAGUENAUER; CORDEIRO FILHO, 2006; MARINHO; LOBATO, 2008; TRACTENBERG; BARBASTEFANO; STRUCHINER, 2010; LAPA; PRETTO, 2010BRITO; MILL, 2012; BARBOSA, 2013; CHAQUIME; FIGUEIREDO, 2013; OLIVEIRA; SILVEIRA, 2014; ASSIS, 2015). Além disso, sabemos que as mesmas tecnologias não estão ao alcance de todos e nem são apropriadas por professores e alunos da mesma forma e com a mesma intensidade. Na verdade, o nosso cenário, apresenta um "expressivo e desigual avanço tecnológico" (DOURADO, 2008, p. 893).

\footnotetext{
${ }^{5}$ Preferimos utilizar o termo professor tutor por acreditar que se trata de um profissional que exerce uma prática pedagógica na EaD. Para maiores detalhes sobre esta discussão ver Garcia (2013).
}

(C) ETD- Educação Temática Digital Campinas, SP $\quad$ v.19 $\quad$ n.1 $\quad$ p. 211-233 jan./mar. 2017 


\section{ESCLARECENDO CONCEITOS}

Alguns conceitos distintos do campo de estudos sobre letramento são tidos, muitas vezes, como sinônimos na área da educação ou são precariamente compreendidos. Um exemplo comum é o uso de alfabetização por letramento e vice-versa. Não é difícil encontrarmos na fala de professores da educação básica esses dois termos serem usados como sinônimos, o que esvazia em grande medida as ideias que eles carregam, em especial, o conceito de letramento, que é muito mais amplo que o da alfabetização. A pesquisa realizada por Lucas (2010) revela que os professores sujeitos de sua investigação relacionavam o processo de letramento ao de alfabetização, considerando-os ora como sinônimos, ora confundindo um com o outro ou ainda percebendo diferenças entre ambos, mas não as sabendo delimitar cada conceito com clareza. Por este motivo e por conta da heterogeneidade terminológica existente no campo, optamos por iniciar nosso diálogo com os leitores deste texto explicitando, ainda que rapidamente, nosso entendimento sobre alfabetização, letramento, letramento digital, multiletramentos, transletramento e novos letramentos. Optamos, a partir de uma revisão histórica dos conceitos, por respeitar a conceitualização original dos autores citados neste texto de modo a avançar com algumas reflexões sobre o tema, ainda que isso nos tenha obrigado a tolerar certa flutuação terminológica e conceitual que é própria do momento vivido por aquele campo de estudo.

Lankshear e Knobel (2011) explicam que, historicamente, o termo letramento era usado para se referir a contextos não formais de ensino e para designar programas de formação de adultos considerados analfabetos ${ }^{6}$, a fim de que estes viessem a adquirir habilidades básicas de leitura e escrita. Era como uma segunda chance para aqueles que tinham uma defasagem nos estudos e que, por esta razão, eram considerados um peso na sociedade, pois não contribuíam para o seu progresso. Com a "crise da leitura" na década de 70, por conta, de maneira geral, do nível de alfabetismo funcional generalizado entre os adultos nos Estados Unidos, em que muitas pessoas estavam sendo pobremente preparadas para enfrentar as mudanças do mundo pós-industrial, pesquisadores alegavam a profunda necessidade de reforma na educação. É desta forma que o significado de letramento começa, a partir de 1980, a sofrer transformações e passa a ser entendido não mais de forma marginal e relacionado com a educação não formal e sim como a possibilidade de melhorar a educação e a formação de cidadãos (LANKSHEAR; KNOBEL, 2011; BUZATO, 2011).

\footnotetext{
${ }^{6}$ Lankshear e Knobel utilizam a palavra illiterate. No entanto, em inglês, não há uma palavra diferente para iletrado e analfabeto, o que exige a análise do contexto pelo leitor. Mas, geralmente, illiterate significa "analfabeto" e "uneducated seria iletrado".
}

(C) ETD-Educação Temática Digital Campinas, SP $\quad$ v.19 $\quad$ n.1 $\quad$ p.211-233 jan./mar. 2017 
Diferentes foram os fatores ${ }^{7}$ que contribuíram para a mudança no entendimento do que vem a ser letramento hoje, mas gostaríamos de destacar as contribuições do educador Paulo Freire que, no contexto do movimento de educação radical, defendeu a ideia de que a prática de ler e escrever necessitava ir além da simples decodificação, implicando o entendimento do mundo, de suas relações sociais e culturais por meio da praxis ${ }^{8}$. Nesta perspectiva freiriana, os não letrados não estão nesta condição por incapacidade ou preguiça, mas por uma questão de injustiça social, por um processo histórico de exclusão que os mantêm na base de uma configuração social hierárquica.

A definição de letramento da qual partimos é a de $\operatorname{KLEIMAN~(1995,~p.~19),~por~ser~}$ uma definição que claramente marca a diferença entre alfabetização e letramento, ao mesmo tempo em que caracteriza o letramento como fenômeno social e não apenas cognitivo: para a autora, letramento é "um conjunto de práticas sociais que usam a escrita, enquanto sistema simbólico e enquanto tecnologia, em contextos específicos, para objetivos específicos". O uso do termo letramentos, no plural, é uma forma de marcar a relação entre letramento, contextos sociais e diferentes sistemas simbólicos, além do alfabeto, envolvidos nas práticas de leitura e escrita. Mais especificamente, que as habilidades requeridas para as práticas de leitura e escrita, os valores ideológicos vinculados a essas habilidades e os efeitos sociais e cognitivos derivados do uso da leitura e escrita variam em diferentes culturas, contextos institucionais e períodos históricos.

A partir da definição acima, a alfabetização passa a ser entendida como uma de variadas e heterogêneas práticas de letramento, cuja especificidade está na finalidade social de propiciar as habilidades e conhecimentos básicos necessários para a leitura e escrita alfabéticas. Normalmente, essa prática se desenvolve no contexto da escolarização. Conforme esclarece Xavier (2002), uma pessoa apenas alfabetizada ainda não experimentou os benefícios que as demais práticas socioculturais oferecerem como, por exemplo, compreensão de textos mais sofisticados e usos mais complexos que envolvem a leitura e escrita. Assim, enquanto a alfabetização é um processo de aquisição de códigos, o

\footnotetext{
7 Lankshear e Knobel (2011) discutem as diferentes razões que estão relacionadas com a mudança no entendimento de letramento.

${ }^{8}$ Conceito inscrito na tradição marxista e gramsciana e central para uma proposta de formação que se deseja crítica. "Uma filosofia da práxis só pode apresentar-se, inicialmente, em uma atitude polêmica e crítica, como superação da maneira de pensar precedente e do pensamento concreto existente (ou mundo cultural existente). E, portanto, antes de tudo, como crítica do "senso comum" (GRAMSCI, 1981, p. 18). Para Noronha (2005) este conceito diz respeito a tornar crítica uma atividade concreta, significa atividade social conscientemente dirigida a um objetivo. Desta forma, a educação é um dos elementos constitutivos da praxis e como tal deve ser lócus fundamental de articulação entre teoria e prática.
}

(C) ETD-Educação Temática Digital Campinas, SP v.19 n.1 $\quad$ p. 211-233 jan./mar. 2017 
letramento é um processo muito mais amplo em que a escrita, a compreensão e a interação estão imbricadas (MARCUSCHI, 2004).

O termo multiletramentos foi cunhado pelo New London Group ${ }^{9}$, em um artigo publicado, em 1996, no Harvard Education Review, como fruto de um manifesto resultante de um colóquio. O grupo desejava explicitar a nova abordagem da pedagogia dos letramentos, que eles denominaram de multiletramentos, necessária diante da multiplicidade de canais de comunicação e da diversidade linguística e cultural presentes no mundo. Para os pesquisadores desse grupo, os multiletramentos superavam as limitações das abordagens tradicionais e contribuíam para que os estudantes tivessem acesso às diferentes linguagens do mundo do trabalho, das suas comunidades e as de poder, valorizadas socialmente, além de promover o engajamento crítico necessário para que eles conseguissem construir seus futuros com sucesso (THE NEW LONDON GROUP, 1996).

Rojo (2012) esclarece que o termo multiletramentos aponta para dois aspectos: a multiplicidade de culturas e a multiplicidade semiótica de constituição dos textos com os quais nos deparamos atualmente e que o prefixo "multi" evidencia exatamente este aspecto, de que não se trata apenas do texto escrito, do impresso, mas também da imagem, do vídeo, da música, da animação, etc. Constitui-se, assim, em avanço quando consideramos as práticas escolares tradicionais. É uma tentativa de ampliar e tornar mais crítica a pedagogia do letramento. Na verdade, os termos letramentos múltiplos e/ou multiletramentos visam destacar que o cidadão letrado, nas sociedades modernas, deverá ser capaz de participar competentemente de diversos letramentos, tanto no que se refere aos diferentes contextos culturais e institucionais de uso da leitura e da escrita (por exemplo, na escola, no trabalho, no lazer, nas atividades cívicas, etc.), quanto no que se refere ao uso de diferentes códigos e linguagens (a escrita alfabética, a representação visual, a comunicação gestual, a comunicação sonora e musical) e diferentes mídias (por exemplo, o corpo, a escrita e o desenho quirográfico, a imprensa, a mídia eletrônica - como rádio e televisão, as mídias digitais). Esclarecemos que multiletramentos é uma tradução mais direta de "multiliteracies", enquanto que letramentos múltiplos é uma adaptação do conceito para o português, preferida por alguns autores.

\footnotetext{
9 The New London Group (Grupo de Nova Londres) é um grupo pioneiro de pesquisadores dos letramentos que, em 1996, publicou um manifesto intitulado "Uma pedagogia dos multiletramentos - desenhando futuros sociais", resultante de um colóquio em Nova Londres, em Connecticut, Estados Unidos. O manifesto argumentava a necessidade da escola se apropriar dos novos letramentos emergentes na sociedade e de considerar as diferenças culturais presentes nas salas de aula. Dentre os seus membros, estão: Courtney Cazden, Bill Cope, Charles William Eliot, Jim Gee, Norman Fairclough, Mary Kalantzis, Allan Luke, Carmen Luke, Martin Nakata e Sara Michaels.
}

(C) ETD- Educação Temática Digital Campinas, SP $\quad$ v.19 $\quad$ n.1 $\quad$ p. 211-233 jan./mar. 2017 
Letramento digital, assim como letramento informacional, letramento visual, entre outros, são termos que buscam especificar os componentes dos assim chamados "multiletramentos" ou "letramentos múltiplos", entendidos como práticas e também como capacidades/habilidades de interpretação. Uma vez que essa especificação é construída teoricamente a partir de uma realidade prática em que os contextos, códigos/linguagens e mídias são misturados ou conectados, esse esforço analítico gera sobrepassagens entre os referentes desses termos (BUZATO, 2009a).

O termo letramento digital não se refere a algo puro e simplesmente relacionado com o computador ou uso de processador de dados, mas se refere, de forma mais ampla, a toda uma gama de novas práticas sociais em que o computador, o software e as redes digitais têm um papel crucial. Não pode ser confundido com a ideia de alfabetização digital, pois, nesta última, o que está em jogo é apenas a aquisição de habilidades básicas para uso das Tecnologias da Informação e Comunicação (TIC). Letramento digital tem a ver com uso, transformação e aplicação consciente das TIC. Na visão de Xavier (2002) implica a realização de práticas de leitura e escrita diferentes das formas tradicionais de letramento e alfabetização, se apresentando como uma necessidade educacional, dadas as mudanças nos modos de ler e escrever os códigos e sinais verbais e não-verbais.

Buzato (2009a, p. 22) propõe uma concepção alternativa de letramentos digitais, não mais como tipos de letramento contrapostos aos tradicionais, mas "como redes complexas e heterogêneas que conectam letramentos (práticas sociais), textos, sujeitos, meios e habilidades que se agenciam, entrelaçam, contestam e modificam mútua e continuamente, por meio, virtude ou influência das TIC". Ainda, esclarece que os letramentos digitais possuem como especificidade propriedades que permitem a hibridização de elementos constitutivos de quaisquer letramentos: (1) formas de mediação (impresso, fotografia, vídeo, cinema, rádio, etc.); (2) sistemas de representação (música, escrita alfanumérica, linguagens imagéticas, etc.); (3) gêneros (provenientes de diferentes esferas de atividade social e tradições culturais que se conectam via TIC; (4) atitudes ou disposições frente ao texto (ler para procurar informação, ler para se divertir, etc.) e (5) letramentos diversos praticados por um mesmo sujeito que transita entre contextos culturais e de prática diferentes.

Consideramos a definição de Buzato (2009a) convergente, em alguma medida, com a noção de transletramentos, uma vez que busca romper com a dicotomização entre letramento dito tradicional e o letramento digital, assim como superar a concepção do sujeito letrado como alguém que busca informação e detém certas habilidades, apontando para tal sujeito como alguém que se engaja com uma rede na qual diferentes papeis,

(C) ETD-Educação Temática Digital Campinas, SP $\quad$ v.19 $\quad$ n.1 $\quad$ p.211-233 jan./mar. 2017 
finalidades e recursos podem/devem ser configurados de forma consciente e crítica, a serviço de determinada trajetória produção de sentido e de aprendizagem. Neste mesmo sentido, encontramos também apoio em Buckingham (2010), que argumenta que letramento digital é muito mais que uma questão funcional de aprender a usar o computador e fazer buscas na internet. Reconhecendo que é preciso começar com o básico, o autor defende a relevância dos sujeitos serem capazes de avaliar e usar criticamente as informações para conseguirem transformá-las em conhecimentos.

O conceito de transletramentos é apresentado por Thomas et al (2007) como a capacidade e a prática sócio-cognitiva de ler, escrever e interagir através de uma série de plataformas, ferramentas e mídias mais antigas (oralidade, escrita à mão, imprensa, televisão, rádio e cinema) até as redes sociais digitais. Este termo abarca não apenas aqueles materiais e práticas baseados no computador, mas todos os tipos de comunicação através do tempo e da cultura. Desta definição, podemos depreender que o conceito de transletramentos se refere à convergência ${ }^{10}$ de letramentos e, portanto, não pode ser pensado separadamente das práticas sociais. Aqui, o impresso atravessa o digital e viceversa, até mesmo porque não podemos nos esquecer que uma nova mídia contém uma antiga mídia. Esse atravessamento, certamente, insere questões a serem pensadas na educação e na sociedade, de maneira geral.

Transletramentos são, dessa forma, práticas sociais em que existe o diálogo entre palavra, imagem e som, onde há a busca por letramentos que ficaram sempre em segundo plano por conta do letramento dominante, desde que a imprensa passou a ser a tecnologia dominante dos letramentos oficiais, isto é, os letramentos ligados às instituições estatais, à ciência, à religião, etc. É um movimento em direção a uma ecologia ao invés de pólos dicotômicos entre o digital e o impresso. Objetiva a justaposição e/ou hibridização não apenas de mídias, mas a relação e o diálogo entre os diferentes, do passado e do presente (THOMAS et al, 2007). Ao mesmo tempo em que acolhe a noção de pluralidade trazida pelos termos letramentos e multiletramentos, esse conceito caminha no sentido contrário ao da especificação e definição de letramentos específicos, delimitado segundo funções sociais, habilidades, contextos, tecnologias ou finalidades específicas. Pretende enfatizar,

\footnotetext{
${ }^{10}$ Aqui, não estamos nos referindo à convergência como um simples processo tecnológico que reúne múltiplas funções dentro de um mesmo aparelho. Mas, no sentido proposto por JenKins (2009) que a define como "fluxo de conteúdos através de múltiplos suportes midiáticos, cooperação entre múltiplos mercados midiáticos e comportamento migratório dos públicos dos meios de comunicação [...] representa transformação cultural, à medida que consumidores são incentivados a procurar novas informações e fazer conexões em meio a conteúdos midiáticos dispersos" (JENKINS, 2009, p. 29).
}

(C) ETD-Educação Temática Digital Campinas, SP $\quad$ v.19 $\quad$ n.1 $\quad$ p.211-233 jan./mar. 2017 
justamente, a fluidez com que o sujeito letrado da atualidade deve aprender a transitar por essa pluralidade em seus percursos de interpretação e de ação pela linguagem, tornando a própria ideia de letramento como algo contingente e, presentemente, avesso às delimitações que conceitos anteriores estabeleceram em face das condições socioculturais e tecnológicas de seus tempos históricos.

Assim, nesta perspectiva, um sujeito transletrado é um ser flexível, que trabalha colaborativamente, que não tem medo de abraçar o novo, de aprender novas habilidades para ser capaz de ler, escrever e interagir através dos múltiplos meios que habitam simultaneamente nosso cotidiano, sejam eles online ou off-line, síncronos ou assíncronos. É um sujeito crítico, que percebe que o modo pelo qual uma informação é apresentada muda a forma como a entendemos, que se responsabiliza pela configuração das tecnologias, práticas, espaços e grupos dos quais participa, ou nos quais se expressa e aprende e/ou ensina.

Já a ideia de novos letramentos se diferencia do letramento tradicional na medida em que implica um novo modo de raciocínio, novas práticas que tem o digital como base e infraestrutura o digital para produzir Discursos, com " $D$ ", no sentido proposto por Gee (2000). Interessante, neste sentido, observar a distinção feita por Buzato (2007, p.125):

\begin{abstract}
Há algo de consideravelmente diferente entre os letramentos ditos tradicionais e os novos letramentos (digitais), mas também algo essencialmente comum entre eles: ao mesmo tempo em que se interpenetram, porque servem a uma mesma sociedade, e porque se servem dos mesmos sistemas semióticos e circulam nas mesmas esferas sociais, se diferenciam porque empregam recursos tecnológicos específicos, ou porque empregam diferentemente os mesmos recursos semióticos nos mesmos gêneros, ou dão ocasião ao surgimento de novos gêneros.
\end{abstract}

Falamos em novos letramentos porque a antiga lógica do letramento tradicional não consegue dar conta dos desafios postos pelas diferentes mídias, textos e novos ambientes que surgiram nos últimos anos. A antiga lógica forma para a passividade enquanto que a sociedade atual exige sujeitos críticos, socialmente responsáveis. Lankshear e Knobel (2011) esclarecem que os novos letramentos se inserem em um novo paradigma, não mais da psicolinguística, mas sim sociocultural. Ressaltam que o uso do termo "novo" deve-se ao desejo de realização de um paralelo com os nomes de iniciativas ou movimentos como a New School of Social Research, a New Science e o New Criticism. Trata-se, desta forma, de uma nova abordagem de pensar o letramento como um fenômeno social.

(C) ETD-Educação Temática Digital Campinas, SP v.19 $\quad$ n.1 $\quad$ p. 211-233 jan./mar. 2017 
Para Lankshear e Knobel (2011), um novo letramento deve ser considerado novo quando ele não se restringe a transferir para uma nova infraestrutura tecnológica as mesmas práticas, atitudes, normas e valores provenientes de letramentos anteriores. Ao invés disso, busca construir um quadro específico de atitudes e valores socioculturais mobilizados pelas novas possibilidades de construção, manipulação e circulação de textos oferecidas pelas tecnologias digitais. É neste ponto que nos interessa pensar novos letramentos na educação a distância, por acreditarmos que a prática pedagógica em ambiente virtual de aprendizagem precisa ser efetivada dentro de um novo paradigma, que alia às novas possibilidades técnicas um novo ethos, uma nova mentalidade.

Discutir novos letramentos e sua relação com a formação de docentes para a EaD se constitui, em nossa visão, em um modo de contribuir para (re) pensar a formação desses sujeitos, provenientes, muitas vezes, de ambientes presenciais e tradicionais de ensino. $\mathrm{Na}$ medida em que estamos discutindo práticas sociais na modalidade a distância, em que se faz intensamente presentes antigas e novas mídias, os transletramentos surgem como possibilidade de qualificar tais práticas, pois busca um novo comportamento e atitude frente a todo e qualquer tipo de letramento, podendo, desta forma, tornar mais críticos e conscientes os usos e apropriações que se faz das tecnologias para promover aprendizagens.

(C) ETD-Educação Temática Digital Campinas, SP v.19 n.1 $\quad$ p. 211-233 jan./mar. 2017 


\section{PRÁTICA PEDAGÓGICA EM EaD E APROPRIAÇÃO TECNOLÓGICA: EM BUSCA DE UMA NOVA POSTURA}

Da poli (ou multi) em direção a transdocência

Ao se discutir prática pedagógica na educação a distância, é preciso refletir sobre os modos como as tecnologias, os ambientes virtuais, as diferentes mídias e textos alteram a dinâmica do processo de ensino e aprendizagem e traz novos desafios aos educadores e estudantes. A discussão precisa ir além da questão do simples acesso, da redução de custos, da ampliação do número de vagas na educação superior e adentrar no campo da permanência com qualidade. Em outras palavras, é preciso pensar a formação por dentro, por meio das práticas cotidianas desenvolvidas nos diversos programas de formação de professores a distância existentes em nosso país.

Muitas críticas são apresentadas à $\mathrm{EaD}$, dentre elas, se destaca a apresentada por Freitas (2007): a de que a maioria dos cursos de formação na modalidade EaD têm se apresentado como uma forma de aligeirar e baratear o processo formativo. Complementando, a autora argumenta que a EaD se trata de uma política compensatória, destinada a suprir a ausência de oferta de cursos regulares para segmentos populacionais historicamente afastados da rede pública de educação superior e que a ação dos tutores se traduz em uma forma precarizada de trabalho na formação superior. No entanto, a própria autora reconhece que a oferta de cursos por instituições públicas de ensino superior representa uma ruptura com programas de formação com viés mercadológico.

Sabemos que a precarização da formação passa, necessariamente, pela discussão da prática docente. $\mathrm{O}$ que não fazem os docentes na $\mathrm{EaD}$ que deveriam fazer? De que prática necessitamos? Quais saberes são imprescindíveis? Indagações estas que também cabem ao ensino presencial. A dificuldade em oferecer respostas às perguntas propostas é que, na $\mathrm{EaD}$, além do uso intenso de diferentes tecnologias, ocorre a passagem de um contexto de trabalho "unidocente" para um contexto "polidocente", em que diferentes sujeitos dividem as responsabilidades pelas atividades (MILL, 2010). Assim, para pensar a prática que queremos é preciso compreender quem são os sujeitos que atuam na formação na modalidade a distância.

O conceito de polidocência apresentado por Mill (2010) se refere a um conjunto de trabalhadores que, mesmo com formações e funções diferentes, é responsável pelo processo de ensino e aprendizagem na $\mathrm{EaD}$. Isto acontece porque, na EaD, a grande quantidade de alunos, atividades, materiais e a organização do ambiente virtual

(C) ETD-Educação Temática Digital Campinas, SP v.19 $\quad$ n.1 $\quad$ p. 211-233 jan./mar. 2017 
impossibilita ou inviabiliza a "unidocência", ou seja, a possibilidade de um único docente ser responsável por conduzir todo o processo educativo, como ocorre, geralmente, no ensino presencial. Desta forma, na educação a distância, diferentes profissionais são responsáveis por produzir o conteúdo, acompanhar e avaliar os alunos, coordenar as atividades, disponibilizar conteúdos no ambiente virtual, gerenciar as salas, coordenar os tutores, converter os materiais de uma mídia para outra (impressa, audiovisual, etc.), constituindo, assim, a polidocência, ou seja, uma docência coletiva, em que cada parte é realizada por um profissional distinto.

Belloni (2003) introduziu esta discussão quando questionava sobre quem ensina na EaD. A autora apresentou o termo professor-coletivo para se referir ao conjunto de educadores em EaD envolvidos no processo de ensino-aprendizagem. No entanto, este termo não nos parece muito apropriado, pois, nesta ordem, sugere que um professor realiza funções diversificadas na EaD. Consideramos que os termos multidocência ou polidocência conseguem ser mais fiéis a ideia da docência coletiva.

Mill (2010) caracteriza os educadores que compõem esta docência coletiva: professor-conteudista, professor-aplicador, projetistas educacionais, tutores virtuais, tutores presenciais, equipe multidisciplinar e equipe coordenadora ${ }^{11}$. No entanto, dependendo das concepções de formação docente e de EaD dos programas e instituições de ensino, nem sempre todos esses profissionais estarão presentes e desenvolvendo as mesmas funções apontadas pela literatura. Há atravessamentos e, por vezes, encontramos o mesmo profissional atuando como tutor no espaço presencial e virtual, como foi o caso do curso semipresencial de Pedagogia da Unesp, em parceria com a Univesp, entre 2010 e 2013. Inclusive, nesse programa de formação de professores em exercício, o tutor recebia o nome de orientador de disciplina, o que também aponta para a complexa discussão sobre o papel exercido por este profissional na EaD. Apesar da diversidade de papéis que compõem a polidocência, acreditamos que o professor-conteudista e o professor-tutor ocupam papel de destaque no processo formativo, por estarem diretamente envolvidos com a prática pedagógica, ou seja, com o conjunto de atividades que possibilita o desenvolvimento e avaliação dos processos intencionais de ensino e que tem por objetivo favorecer a aprendizagem (MARCELO GARCÍA, 2001).

\footnotetext{
${ }^{11}$ Mill (2010) também descreve as funções de cada um desses educadores. Pela delimitação deste espaço, optamos apenas por citar os nomes dos educadores da polidocência.
}

(C) ETD-Educação Temática Digital Campinas, SP v.19 $\quad$ n.1 $\quad$ p. 211-233 jan./mar. 2017 
A qualidade da prática pedagógica na EaD passa pelo desafio da aproximação entre o trabalho do professor conteudista e o do professor tutor (GARCIA, 2013). Essa aproximação é necessária devido ao afastamento temporal entre a elaboração do material didático e a prática pedagógica desenvolvida com os alunos (LAPA; PRETTO, 2010). Geralmente, o professor autor (professor-conteudista) dos materiais não é o responsável pela mediação, tarefa delegada ao professor tutor. Além disso, estão presentes nos materiais concepções e crenças do professor autor e não, necessariamente, do professor tutor e cabe a este dar conta de uma proposta pedagógica elaborada por outro profissional. Em outras palavras, o professor-tutor, geralmente, não participa da organização da disciplina nem da produção do material a ser trabalhado com os alunos e tem que se desdobrar para se apropriar do processo pedagógico, sendo ainda, muitas vezes, visto como em papel secundário do processo de ensino e aprendizagem. Contudo, esta fragmentação pode ser minimizada se a instituição de ensino oferecer formação continuada aos seus profissionais, proporcionando encontros em que professor conteudista e professor tutor possam discutir e (re) pensar a disciplina colaborativamente, inclusive, considerando as necessidades postas pelos estudantes ao longo da disciplina. Considerando que a permanência de diferentes entendimentos sobre formação a distância ${ }^{12}$, avaliação e apropriação tecnológica entre quem cria a disciplina e quem a desenvolve com os alunos pode promover descaracterizações de processos formativos idealizados originalmente na proposta pedagógica, a aproximação entre estes dois profissionais pode contribuir para evitar o fracasso de iniciativas e programas de formação a distância.

Há, ainda, dois aspectos que devem ser pontuados sobre a polidocência em EaD que apresentam implicações ao magistério superior: a fragmentação do processo de trabalho e a colaboração que daí pode decorrer. Se por um lado temos a interdependência entre os diferentes profissionais, o que pode conduzir à produção articulada e colaborativa, por outro, temos a fragmentação do trabalho que, inserido na lógica da divisão do trabalho no sistema capitalista, pode desencadear a redução da autonomia e do entendimento do todo que acontece nesta modalidade de ensino. Teríamos, então, os que concebem e decidem os pressupostos da proposta pedagógica, a organização do ambiente virtual e os que executam as atividades.

Desta forma, para além de uma poli (ou de uma multi), seria pertinente caminhar para uma transdocência, em que os papéis se atravessam, não apenas de professor

12 Garcia et al (2015) discute diferentes concepções que tutores possuem sobre aspectos da formação a distância.

(C) ETD- Educação Temática Digital Campinas, SP $\quad$ v.19 $\quad$ n.1 $\quad$ p. 211-233 jan./mar. 2017 
conteudista e professor tutor, mas de designer instrucional, de aluno, de docente, ou seja, daqueles que compõem a docência coletiva. Isto exigira o desenvolvimento de novos letramentos dos profissionais e tornaria o trabalho menos fragmentado e mais colaborativo e consciente, além de possibilitar que alunos e professores assumam papéis mais ativos, de protagonistas no processo de ensino e aprendizagem. A transdocência, de modo semelhante aos transletramentos e por ele permeada, acolhe a noção de pluralidade, principalmente em relação aos papéis desempenhados por todos os envolvidos no processo de ensino e aprendizagem a distância e tem todas as condições de efetivar uma prática pedagógica comprometida com a inclusão, democracia, aprendizagem e conscientização, por meio de práticas sociais que inserem os sujeitos na diversidade de usos e funções das diferentes tecnologias presentes na sociedade contemporânea.

\section{TRANSLETRAMENTOS: UMA REFERÊNCIA PARA A REFLEXÃO SOBRE E AÇÃO DE APROPRIAÇÃO TECNOLÓGICA CRÍTICA EM EaD}

As tecnologias na educação, seja ela presencial ou a distância, não podem ser compreendidas sem considerarmos a sociedade que a produziu, as pessoas que as usam e as relações que as envolvem. É preciso olhar para a tecnologia como uma criação humana e pensar os modos pelos quais ela é praticada, o modo como iremos nos apropriar dela, tendo em vista, porém, que ela não se dobra docilmente a todos os nossos interesses porque traz inscrita, em seu design e seu modo de funcionamento, interesses dos seus produtores, que representam resistência a nossos movimentos de apropriação. É neste ponto que os novos letramentos nos ajudam a refletir sobre as práticas sociais desenvolvidas, os significados produzidos e as relações de poder estabelecidas.

Em decorrência da mediação didático-pedagógica na modalidade a distância ocorrer com a utilização de diferentes mídias e tecnologias de informação e comunicação, é importante refletir sobre apropriação tecnológica. Bar et al (2007, p.1.) define-a como "uma negociação do poder e controle implicado na configuração das tecnologias, nos seus usos e na distribuição de seus benefícios", em um ciclo que começa com a adoção da tecnologia como ela foi fabricada, ocorrendo posteriormente um processo de apropriação propriamente dito, isto é, a transformação por meio das práticas e necessidades locais da tecnologia em suas funções, aparências, configuração e até mesmo em sua utilização; e, por último, a reapropriação dessas transformações pelo fabricante, que reconfigura o seu produto, incorporando ou não-as apropriações a partir de seus interesses. Contudo, Buzato

(C) ETD-Educação Temática Digital Campinas, SP v.19 $\quad$ n.1 $\quad$ p. 211-233 jan./mar. 2017 
(2010), ao discutir a apropriação tecnológica como uma inovação ascendente (bottom-up), argumenta que esta definição não abrange a complexidade que envolve a questão.

Há duas grandes correntes a respeito da relação entre a tecnologia e sociedade, as quais podem ser expressas pelas metáforas da tecnologia como salvação e da tecnologia como ferramenta neutra, discutidas por Garcia et al (2011), Buzato (2009b) e Peixoto (2009), entre outros. A metáfora da tecnologia como salvação faz referência ao determinismo tecnológico, ou seja, à ideia de que a tecnologia, por si mesma, consegue produzir mudanças nas capacidades cognitivas individuais dos seres humanos e na sociedade e, portanto, na educação, sendo capaz de introduzir, por si só, um novo paradigma ou modelo pedagógico. Warschauer (2003, p. 271) aponta o risco de pensar o computador como uma máquina onipotente, desconsiderando tanto o uso como o contexto, na transposição de modelo "ígneo" de tecnologia educacional, no qual o computador na sala de aula "geraria automaticamente aprendizado, da mesma maneira que o fogo gera automaticamente calor", reduzindo, assim, a capacidade do homem de controlar o desenvolvimento técnico, que estaria além de seu controle devido à autonomia e eficácia técnica da máquina onipotente.

A metáfora da ferramenta neutra, por sua vez, vai em sentido oposto, isto é, enquanto o determinismo atribui poder e autonomia à tecnologia, estruturando os usos que dela podem ser feitos, o instrumentalismo supervaloriza a ação do homem sobre o meio técnico e concebe a tecnologia como flexível, passível de ser modelada pelo usuário. Nesta concepção, a tecnologia é confundida com instrumento e serve para facilitar e mediar processos de aprendizagem. Seria "uma ferramenta neutra, indiferente às finalidades, apenas uma peça metálica utilizável para qualquer propósito" (WARSCHAUER, 2003, p. 271). No entanto, quando reduzida a instrumento/ferramenta, a tecnologia apenas dinamiza práticas pedagógicas já existentes e se esquece de problematizar os sentidos que elas trazem bem como os que são produzidos pelos seus usos. A ideia subjacente é a de que nós usamos o livro, o computador, a TV, etc. da forma como queremos, porque somos nós que controlamos a tecnologia e não vice-versa. No entanto, não existe neutralidade no instrumento, pois este, como esclarece Buzato (2009b), ao se relacionar com outros atores, em outras circunstâncias e ações, transforma o seu próprio design e o seu significado, assim como a natureza da atividade a que se presta. Para elucidar, o autor apresenta o exemplo da faca, bisturi e navalha que exemplifica bem o movimento de que o objeto não pode ser pensado nem compreendido fora da relação com o seu praticante e o curso de suas ações e escolhas, as quais não são completamente (ou mesmo nem em parte) previsíveis e controláveis.

(C) ETD-Educação Temática Digital Campinas, SP v.19 $\quad$ n.1 $\quad$ p. 211-233 jan./mar. 2017 
Para uma prática pedagógica crítica, se faz necessário superar dessas duas concepções que têm como pressuposto, respectivamente, a autonomia/onipresença do objeto técnico e a neutralidade cultural/ideológica. Ambas pensam tecnologia e prática social separadamente: numa a tecnologia determina a prática, na outra, a prática determina a tecnologia. Além disso, não podemos nos esquecer de que, nas instituições de ensino, as tecnologias podem ser utilizadas para atender a diferentes teorias de aprendizagem e, por esta razão, argumentamos que não é qualquer apropriação que contribuirá para a formação de um sujeito letrado, ou melhor, transletrado, mas somente uma apropriação crítica das tecnologias, que concebe as TIC enquanto objeto, conhecimento, rede conectada, enquanto política permeada pelos interesses de quem a produziu. Convém ressaltar que, apesar das tecnologias digitais serem fundamentais para a atividade social, para a implementação de novas relações e práticas que caracterizem uma nova mentalidade, não são as tecnologias que a nova mentalidade, nem o seu uso é totalmente controlável pelos sujeitos (BUZATO, 2009c).

A relação entre os novos letramentos e apropriação tecnológica crítica pode ser pensada a partir da teoria sobre o consumo de Certeau (1994), para quem os "miúdos" do dia a dia escolar, e as maneiras de fazer dos diferentes sujeitos apontam para as formas como consomem a cultura e as estruturas criadas por outros. Para o autor, as pessoas não agem (ou consomem) exatamente aquilo que grupos hegemônicos produzem. Elas subvertem a ordem, possuem engenhosidades, táticas silenciosas que permite ao fraco (neste caso, o professor, o aluno) tirar partido do forte (instituições, sistemas, corporações, etc.). Toda tecnologia carrega consigo brechas que permitem a realização de adaptações, transformações e expressão de subjetividades, as quais não estão previstas e autorizadas e se constituem em transgressão, em resistência propositiva.

Buzato (2010) aborda a questão da apropriação tecnológica como apropriação participativa esclarecendo que:

Ao participarem de atividades em que a tecnologia é relevante, as pessoas adaptam e modificam o significado da mesma, por meio da interação social (negociação de sentidos) em torno de seus usos; mas também de que, ao fazê-lo, as pessoas vão transformando a si mesmas. Apropriação, portanto, passa de uma precondição a um sinônimo de transformação. Apropriar-se é igual a tornar-se (BUZATO, 2010, p. 290).

Portanto, apropriação crítica envolve inovações ascendentes (de baixo para cima) por parte dos utilizadores que não criaram as tecnologias originalmente. Dito de outra forma, os sujeitos, com suas diferentes visões, interesses, competências e necessidades,

(C) ETD-Educação Temática Digital Campinas, SP v.19 $\quad$ n.1 $\quad$ p. 211-233 jan./mar. 2017 
compartilham seus usos e ajustes entre si e, assim, produzem inovações abertas, voltadas para resolver os seus problemas locais. Deste modo, a rede colaborativa criada pelo compartilhamento também é permeada por negociações e conflitos e é nesta tensão que resulta a inovação criativa e um movimento de resistência a arquiteturas de exploração, que tende a retirar dos sujeitos o seu movimento de apropriação crítica das tecnologias.

No contexto da educação a distância, a apropriação tecnológica crítica anda de mãos dadas com o conceito de transletramentos e a transdocência. Os transletramentos, por determinarem uma referência para a reflexão e ação sobre o conceito de letramento, promovem a sua descompartimentalização, além de incorporar e atravessar práticas sociais não previstas pelo letramento tradicional, as quais são importantes na modalidade de ensino a distância e em nossa sociedade tecnologizada. Já a transdocência prevê um processo de descompartimentalização dos diferentes papéis que compõem a multi ou polidocência e, até mesmo, de linguagens, tecnologias e contextos institucionais, possibilitando que os diferentes profissionais envolvidos na EaD sejam capazes de conduzir competentemente diversas práticas sociais relevantes para a formação de professores em ambiente virtual, ou seja, marcado por tecnologias de ontem e de hoje.

Nesse sentido, o que chamamos de transletramentos é um convite para que o sujeito (aluno, professor, tutor, etc.) transite por esses compartimentos (letramentos) que estão dados, ora atuando conforme se espera em cada um deles, ora justapondo-os, traduzindo-os, combinando-os e, assim fazendo, desconstruindo as compartimentalizações dadas até então. Isto nos remete ao conceito de apropriação crítica, que não significa negar o que está dado, mas, a partir do que está dado, transformar o que a tecnologia é, e o que ele mesmo, sujeito, pode vir a ser. A transdocência pode ajudar neste sentido, superando as delimitações presentes no processo de ensino e aprendizagem, no currículo, na organização do ambiente virtual, nos conteúdos, nos usos das tecnologias, nos papéis de "especialista" e nas relações de autoridade e de função dadas aos atores (alunos, instituição, docente, designer, tecnologia, etc.), e mesmo as compartimentalizações de tempo e espaço que se traduzem em tecnologias como "sala de aula", "carga horária", "presença" e "ausência". Os sujeitos da transdocência, ao usarem as tecnologias presentes na $\mathrm{EaD}$, se inserem, ao mesmo tempo, em práticas sociais de uso de leitura e escrita, que constituem uma forma de apropriação tecnológica poderosa atualmente, e que podem e devem ser buscada no âmbito da docência e da formação docente.

(C) ETD-Educação Temática Digital Campinas, SP v.19 $\quad$ n.1 $\quad$ p. 211-233 jan./mar. 2017 
Acreditamos que professores-conteudistas, alunos, professores-tutores e demais atores da EaD necessitam, em seus contextos, encontrar maneiras colaborativas de se apropriar criticamente das diferentes tecnologias, de modo a negociar criativamente os modelos impostos de currículo, de tempos e espaços de ensino e aprendizagem, de uso das tecnologias, das relações de autoridade e funções dadas aos autores e, por meio dessa apropriação crítica, desenvolver autonomia e consciência sobre os novos mecanismos hegemônicos que buscam submeter e direcionar o trabalho docente. E, para este desafio, os transletramentos se constituem uma referência para a reflexão e ação voltada para a construção de novas práticas sociais no processo de formação de professores a distância, por exigir participação ativa, crítica e reflexiva e possuir uma nova mentalidade condizente com a cultura da convergência.

\section{CONSIDERAÇÕES FINAIS}

Para a construção de uma nova EaD, pensamos ser importante investir na construção de uma nova mentalidade entre os atores da transdocência, em especial, professores tutores e professores conteudistas, para que seja possível promover novos usos, novas práticas sociais, que contribuam para a superação daquelas já cristalizadas e provenientes de contextos tradicionais de ensino, que pouco ou nada questionam os usos que se faz da tecnologia e os seus significados e papel na formação profissional e mesmo na vida pessoal dos estudantes.

Evidenciamos os transletramentos como uma referência para a reflexão e ação voltada para a implementação dessa mudança, uma vez que vivemos, aprendemos e nos comunicamos num mundo marcado por diferentes letramentos e múltiplas mídias, as quais não são estanques, mas usadas cotidianamente de forma híbrida Tal modelo de letramento torna-se, desta forma, relevante no contexto da educação a distância, exatamente porque opera dentro de um novo paradigma e possui uma nova mentalidade em que os usos das diferentes tecnologias devem se dar por meio de uma apropriação crítica, para além do texto escrito, já que tantas outras tecnologias também precisam ser lidas e usadas competentemente.

O transletramento busca, mais profundamente, transformar sujeitos em cidadãos críticos, conscientes, portadores de uma postura mais ativa e colaborativa frente às questões que lhe são apresentadas nos diferentes contextos em que estão inseridos. Constitui-se, assim, numa possibilidade para repensar o currículo, as experiências, os modos de agir, de pensar e de se relacionar com as pessoas que ensinam e aprendem na educação

(C) ETD-Educação Temática Digital Campinas, SP v.19 $\quad$ n.1 $\quad$ p. 211-233 jan./mar. 2017 
a distância. Trata-se, no nosso entendimento, de um campo de estudos da área da linguagem que pode contribuir muito para a educação e, neste caso, para qualificar a formação de professores a distância, rompendo com concepções e projetos de formação reducionistas e utilitaristas, voltados unicamente para o mercado de trabalho, com pouco ou nenhum comprometimento com uma formação sólida, crítica e cidadã.

Sabemos da impossibilidade de existência de uma única prática pedagógica na EaD. Cada curso ou programa nessa modalidade está inserido num local, pertence a uma dada instituição, está direcionado a um público alvo específico e possui determinadas finalidades (BUZATO, 2009b). No entanto, é possível e desejável que as diferentes práticas vividas nas instituições de $\operatorname{EaD}$ no Brasil busquem refletir e lidar com a questão da apropriação tecnológica, percebendo o modo como seus atores a concebem e a conduzem em sua prática de formação de professores, favorecendo possibilidades de inovação e transformação da educação superior a distância.

\section{REFERÊNCIAS}

ASSIS, Luciana Elias de. Educação e tecnologias: O novo ritmo da informação. Bolema: Boletim de Educação Matemática, Rio Claro, SP, v. 29, n. 51, p. 428-434, abr. 2015. Disponível em: <http://goo.gl/hN33W5 >. Acesso em: 10 dez. 2015. ISSN 1980-4415.

BAR, François; PISANI, Francis; WEBER, Matthew. Mobile technology appropriation in a distant mirror: baroque infiltration, creolization and cannibalism. In: SEMINARIO SOBRE DESARROLLO ECONÓMICO, DESARROLLO SOCIAL Y COMUNICACIONES MÓVILES EN AMÉRICA LATINA. Anais eletrônicos... Buenos Aires, Argentina. abr. 2007. Disponível em: <http://goo.gl/gR9nLf>. Acesso em: 15 jun. 2015.

BARBOSA, Márcia Aparecida. O tutor na educação a distância e redes colaborativas de aprendizagem. Colloquium Humanarum, Presidente Prudente, SP, v. 10, p. 1156-1163. jul./dez. 2013. Disponível em: <http://goo.gl/pQmf6e> Acesso em: 10 dez. 2015. ISSN 1809-8207.

BELLONI, Maria Luiza. Educação a distância. 3 ed. Campinas: Autores Associados, 2003. Disponível em: <http://goo.gl/sWheB1>. Acesso em: 10 dez. 2015.

BRASIL. Lei n. 9.394, de 20 de dezembro de 1996. Estabelece as Diretrizes e Bases da Educação Nacional. Diário Oficial da União, Brasília, DF. Disponível em: <http://goo.gl/oXee3>. Acesso em: 10 dez. 2015.

BRASIL. Lei n. 13.005 de 25 de junho de 2014. Plano Nacional de Educação - PNE. Disponível em: <http://goo.gl/5CtxmT>. Acesso em: 10 abr. 2015.

(C) ETD-Educação Temática Digital Campinas, SP v.19 n.1 $\quad$ p. 211-233 jan./mar. 2017 
BRASIL. Referenciais de qualidade para educação superior a distância. Brasília, 2007. Disponível em: <http://goo.gl/EENliQ >. Acesso em: 10 dez. 2015.

BRITO, Nara. Dias; MILL, Daniel. Estudo sobre a aprendizagem da docência na atuação na educação a distância: uma análise da percepção dos professores. In: SIMPÓSIO INTERNACIONAL DE EDUCAÇÃO A DISTÂNCIA E ENCONTRO DE PESQUISADORES EM EDUCAÇÃO A DISTÂNCIA. Anais eletrônicos... São Carlos: UFSCar, 2012. p. 01-06. Disponível em: <http://goo.gl/cN1vXO>. Acesso em: 02 fev. 2016.

BUCKINGHAM, David. Cultura digital, educação midiática e o lugar da escolarização. Educação e Realidade, Porto Alegre, RS, v. 35, n. 03, p. 37-58. set./dez. 2010. Disponível em: <http://goo.gl/Woi98J >. Acesso em: $10 \mathrm{dez}$. 2015. ISSN 2175-6236.

BUZATO, Marcelo El Khouri. Letramentos multimodais críticos: contornos e possibilidades. Crop, São Paulo, SP, v. 12, p. 108-144. 2007. Disponível em: <http://200.144.182.130/revistacrop/images/stories/edicao12/v12a07.pdf>. Acesso em: 10 dez. 2015. ISSN 2177-5478.

BUZATO, Marcelo El Khouri. Letramento e inclusão: do Estado-Nação à era das TIC. DELTA: Documentação de Estudos em Linguística Teórica e Aplicada, São Paulo, SP, v. 25, n. 01, p. 01-38. 2009a. Disponível em: <http://goo.gl/Zj97NH>. Acesso em: 10 dez. 2015. ISSN 1678-460X. BUZATO, Marcelo El Khouri. Letramento, novas tecnologias e a teoria ator-rede: um convite à pesquisa. Remate de Males, Campinas, SP, v. 29. jan./jun. 2009b. Disponível em: <http://goo.gl/noUxx0>. Acesso em: $10 \mathrm{dez}$. 2015. ISSN 0103-183X.

BUZATO, Marcelo El Khouri. Tecnologia, espaciotemporalidade e educação: contribuições dos estudos sobre novos letramentos para uma reflexão sobre EAD e universidade no Brasil. In: SEMINÁRIO DE EDUCAÇÃO À DISTÂNCIA DA FACULDADE DE EDUCAÇÃO, 2., 2009, Campinas, SP. Anais eletrônicos... Campinas, p. 01-23, 2009.

BUZATO, Marcelo El Khouri. Cultura digital e apropriação ascendente: apontamentos para uma educação 2.0. Educação em Revista, Belo Horizonte, MG, v. 26. n. 03. p. 283-304. dez. 2010. Disponível em: <http://goo.gl/Qch70r>. Acesso em: 10 dez. 2015. ISSN 0102-4698.

BUZATO, Marcelo El Khouri. Novos letramentos e novos parâmetros para a inovação educacional na perspectiva da teoria ator-rede. In: FONTOURA, Helena Amaral da; SILVA, Marco (Orgs.). Práticas pedagógicas, linguagem e mídias: desafios à pós-graduação em Educação em suas múltiplas dimensões. Rio de Janeiro: ANPEd Nacional, 2011. p. 99-115. Disponível em: <http://goo.gl/YfCwKl>. Acesso em: 10 dez. 2015.

CAZDEN, Courtney; COPE, Bill; FAIRCLOUGH, Norman; GEE, J; et al. A pedagogy of multiliteracies: designing social futures. Harvard Educational Review, v. 66, p. 60-92. 1996. Disponível em: <http://goo.gl/NOPIkm>. Acesso em: 10 dez. 2015.

CHAQUIME, Luciane Penteado; FIGUEIREDO, Ana Paula Silva. O papel do designer instrucional na elaboração de cursos de educação a distância: exercitando conhecimentos e relatando a

(C) ETD-Educação Temática Digital Campinas, SP $\quad$ v.19 n.1 $\quad$ p. 211-233 jan./mar. 2017 
experiência. In: CONGRESSO BRASILEIRO DE ENSINO SUPERIOR A DISTÂNCIA, 10., 2013, Belém, PA. Anais eletrônicos... Belém: UniRede, p. 01-13, 2013. Disponível em: <http://goo.gl/UNhr8H >. Acesso em: 12 fev. 2016.

CERTEAU, Michel de. A invenção do cotidiano: artes de fazer. 5 ed. Petrópolis: Vozes, 1994. Disponível em: <http://goo.gl/mo8V6j>. Acesso em: 10 dez. 2015.

COSTA, Arkana Kelly Silva; HARRIS, Ana Lúcia Nogueira de Camargo. Estado atual da Educação a Distância e seu uso como apoio ao ensino em cursos de graduação em Engenharia Civil no Estado de São Paulo. In: CONGRESSO BRASILEIRO DE ENSINO DE ENGENHARIA, 23., 2005, Campina Grande, PB. Anais eletrônicos... Campina Grande: Cobenge, p. 01-11, 2015. Disponível em: <http://goo.gl/iPTmlq>. Acesso em: 12 fev. 2016.

DOURADO, Luiz Fernandes. Políticas e gestão da educação superior a distância: novos marcos regulatórios. Educação e Sociedade, Campinas, SP, v. 29, n. 104, p.891-917. out. 2008. Disponível em: <http://goo.gl/5jgwJO > Acesso em: 10 dez. 2015. ISSN 1678-4626.

FREITAS, Helena Costa Lopes de. A (nova) política de formação de professores: a prioridade postergada. Educação e Sociedade, Campinas, SP, v. 28, n. 100, p.1203-1230. out. 2007. Disponível em: <http://goo.gl/8NI93z>. Acesso em: 10 dez. 2015. ISSN 1678-4626.

GARCIA, Marta Fernandes. Prática do professor tutor na formação superior de professores a distância: criação e validação de um instrumento de pesquisa. 2013. 126 f. Dissertação (Mestrado em Educação) - Faculdade de Educação, Universidade Estadual de Campinas, Campinas, SP, 2013. Disponível em: <http://goo.gl/8XtwU7> Acesso em: 10 dez. 2015.

GARCIA, Marta Fernandes; RABELO; Dóris Firmino; SILVA, Dirceu; AMARAL, Sérgio Ferreira. Novas competências docentes frente às tecnologias digitais interativas. Teoria e Prática da Educação, Maringá, PR, v. 14, n. 01, p. 79-87. jan./abr. 2011. Disponível em: <http://goo.gl/eLRwwA >. Acesso em: 10 dez. 2015. ISSN 2237-8707.

GARCIA, Marta Fernandes; SILVA, Dirceu; RIEDO, Cássio Ricardo Fares. Formação de professores a distância: o que pensam os tutores? Revista Ibero-Americana de Estudos em Educação, Araraquara, SP, v. 10, n. 01, p. 67-82. 2015. Disponível em: <http://goo.gl/j103SV > Acesso em: 10 dez. 2015. ISSN 1982-5587.

GEE, James Paul. Teenagers in new times: a new literacy studies perspective. Journal of Adolescent and Adult Literacy, v. 43, n. 05, p. 412-420. 2000. Disponível em: <http://goo.gl/imuvnQ>. Acesso em: 10 dez. 2015. ISSN 1936-2706.

GRAMSCI, Antonio. A concepção dialética de História. 4. ed. Rio de Janeiro, Civilização Brasileira, 1981. Disponível em: <http://goo.gl/9LEkpb>. Acesso em: 10 dez. 2015.

(C) ETD-Educação Temática Digital Campinas, SP v.19 n.1 $\quad$ p. 211-233 jan./mar. 2017 
JENKINS, Henry. Cultura da convergência: a colisão entre os velhos e os novos meios de comunicação. 2. ed. São Paulo: Aleph, 2009. Disponível em: <http://goo.gl/R6cP80>. Acesso em: 10 dez. 2015.

KLEIMAN, Angela Bustos de. Modelos de letramento e as práticas de alfabetização na escola. In: KLEIMAN, Angela Bustos de (Org.). Os significados do letramento: uma nova perspectiva sobre a prática social da escrita. Campinas: Mercado de Letras, 1995.

LANKSHEAR, Colin; KNOBEL, Michele. New literacies: everyday practices and social learning. Open University Press, 2011. Disponível em: <http://goo.gl/DFmz1B>. Acesso em: 10 dez. 2015.

LAPA, Andrea; PRETTO, Nelson De Luca. Educação a distância e precarização do trabalho docente. Em Aberto, Brasília, v. 23, n. 84, p.79-97. nov. 2010. Disponível em: <http://goo.gl/45b6Ah>. Acesso em: 10 dez. 2015.

LUCAS, Maria Angélica Olivo Francisco. Reflexões sobre os conceitos de alfabetização e letramento apresentados por professores de educação infantil. Teoria e Prática da Educação, Maringá, PR, v. 13, n. 03, p. 109-119. set./dez. 2010. Disponível em: <http://goo.gl//NmDqN>. Acesso em: 10 dez. 2015. ISSN 2237-8707.

MARCELO GARCÍA, Carlos. Rediseño de la práctica pedagógica: factores, condiciones y procesos de cambio en los teleformadores. Conferencia impartida en la reunión técnica internacional sobre el uso de tecnologías de la información en el nivel de formación superior avanzada, Sevilla, Espanha, 2001.

MARCUSCHI, Luiz Antônio. Da fala para a escrita: atividades de retextualização. São Paulo: Cortez, 2004.

MARINHO, Simão Pedro; LOBATO, Wolney. Tecnologias digitais na educação: desafios para a pesquisa na pós-graduação em educação. In: COLÓQUIO DE PESQUISA EM EDUCAÇÃO, 6., Belo Horizonte, MG, 2008. Anais eletrônicos... Belo Horizonte, 2010 p. 01-09. Disponível em:

<http://goo.gl/ItxRD3>. Acesso em: $10 \mathrm{dez} .2015$.

MELLO, Guiomar Namo de. Formação inicial de professores para a educação básica: uma (re) visão radical. São Paulo em Perspectiva, São Paulo, SP, v. 14, n. 01. jan./mar. 2000. Disponível em: <http://goo.gl/HYF2Gb>. Acesso em: $10 \mathrm{dez}$. 2015. ISSN 1806-9452.

MILL, Daniel. Sobre o conceito de polidocência ou sobre a natureza de trabalho pedagógico na Educação a Distância. In: MILL, Daniel; RIBEIRO, Luis Roberto de Camargo; OLIVEIRA, Marcia Rozenfeld Gomes de (Org.) Polidocência na educação a distância: múltiplos enfoques. São Carlos: EDUFSCar, 2010.

NORONHA, Olinda Maria. Práxis e educação. HISTEDBR On-line, Campinas, SP, n. 20, p. 86-93. dez. 2005. Disponível em: <http://goo.gl/GdPzWl>. Acesso em: 10 dez. 2015. ISSN 1676-2584.

(C) ETD-Educação Temática Digital Campinas, SP v.19 n.1 $\quad$ p. 211-233 jan./mar. 2017 
OLIVEIRA, Altemar Sales de; HAGUENAUER, Cristina; CORDEIRO FILHO, Francisco. Uso de ambientes informatizados na prática do professor de informática do ensino superior privado. Colabor@ - A Revista Digital da CVA-RICESU, Porto Alegre, RS, v. 03, n. 12, p. 01-13. out. 2006. Disponível em: <http://goo.gl/zmJXXF>. Acesso em: 10 dez. 2015. ISSN 1519-8529.

OLIVEIRA, Carolina Dias de; SILVEIRA, Ricardo Azambuja. Avaliação do uso das ferramentas tecnológicas em ambientes virtuais de ensino e aprendizagem em educação a distância: um estudo de caso do E-TEC/CEFET-MG. In: CONGRESSO BRASILEIRO SE ENSINO SUPERIOR A DISTÂNCIA, 9., 2014, Florianópolis, SC. Anais eletrônicos... Florianópolis: UniRede, 2014. p. 95-108. Disponível em: <http://goo.gl/ayF4uh>. Acesso em: 12 fev. 2016.

PEIXOTO, Joana. Tecnologia na educação: uma questão de transformação ou de formação? In: GARCIA, Dirce Maria Falcone; CECÍLIO, Sálua. (Org.). Formação e profissão docente em tempos digitais. Campinas: Alínea, 2009. p. 217-235.

ROJO, Roxane. Pedagogia dos multiletramentos: diversidade cultural e de linguagens na escola. In: ROJO, Roxane; MOURA, Eduardo. Multiletramentos na escola. São Paulo: Parábola Editorial, 2012, p. 11-31.

SANTOS, Edméa Oliveira dos; TRACTENBERG, Leonel; PEREIRA, Máira. Competências para a docência online: implicações para formação inicial e continuada de professores-tutores do FGV online. In: CONGRESSO INTERNACIONAL DE EDUCAÇÃO A DISTÂNCIA, 12., 2005, Florianópolis, SC. Anais eletrônicos... Florianópolis: ABED, 2005. p. 01-10. Disponível em: <http://goo.gl/oxKps8>. Acesso em: 12 fev. 2016.

THOMAS, Sue; JOSEPH, Chris. LACCETTI, Jess; MASON, Bruce; MILLS, Simon; PERRIL, Simon; PULLINGER, Kate. Transliteracy: crossing divides. First Monday, v. 12 n. 12. 2007. Disponível em: <http://goo.gl/oHlkBE >. Acesso em: 10 dez. 2015. ISSN 1396-0466.

TRACTENBERG, Leonel; BARBASTEFANO, Rafael; STRUCHINER, Miriam. Ensino colaborativo online (ECO): uma experiência aplicada ao ensino da Matemática. BOLEMA: Boletim de Educação Matemática, Rio Claro, SP, v. 23, n. 37, p. 1037-1061. 2010. Disponível em: <http://goo.gl/Q1pdXB >. Acesso em: 10 dez. 2015. ISSN 1980-4415.

WARSCHAUER, Mark. Tecnologia e inclusão social: a exclusão social em debate. São Paulo: Editora SENAC, 2003.

XAVIER, Antonio Carlos dos Santos. Letramento digital e ensino. Disponível em: <http://goo.gl/ec9WJn>. Acesso em: 06 jul. 14.

\footnotetext{
i Revisão gramatical do texto pela equipe da revista ETD
} 